Article

\title{
Graphene Nanosheets Based Cathodes for Lithium-Oxygen Batteries
}

\section{Padmakar Kichambare * and Stanley Rodrigues}

Air Force Research Laboratory, Aerospace Systems Directorate, Wright-Patterson Air Force Base, Dayton, OH 45433-7252, USA; E-Mail: Stanley.Rodrigues@us.af.mil

* Author to whom correspondence should be addressed;

E-Mail: Padmakar.Kichambare.1.ctr@us.af.mil; Tel.: +1-937-255-1155; Fax: +1-937-656-7266.

Academic Editor: Rüdiger Schweiss

Received: 29 June 2015 / Accepted: 14 October 2015 / Published: 20 October 2015

\begin{abstract}
Lithium-oxygen batteries have attracted considerable attention as a promising energy storage system. Although these batteries have many advantages, they face several critical challenges. In this work, we report the use of graphene nanosheets (GNSs), nitrogen-doped graphene nanosheets ( $N$-GNSs), exfoliated nitrogen-doped graphene nanosheets (Ex- $N$-GNSs), and a blend of Ex- $N$-GNSs with nitrogen-doped carbon (Hybrid 1 ) as oxygen cathodes. These cathode materials were characterized by the Brunauer-Emmett-Teller (BET) surface area analysis, cyclic voltammetry (CV) and scanning electron microscopy (SEM). In order to mitigate safety issues, all solid-state cells were designed and fabricated using lithium aluminum germanium phosphate (LAGP) as ceramic electrolyte. The cathodes prepared from GNSs, $N$-GNSs, Ex- $N$-GNSs, and Hybrid 1 exhibit remarkable enhancement in cell capacity in comparison to conventional carbon cathodes. This superior cell performance is ascribed to beneficial properties arising from GNSs and nitrogen doped carbon. GNSs have unique morphology, higher oxygen reduction activity, whereas nitrogen-doped carbon has higher surface area.
\end{abstract}

Keywords: nitrogen-doped graphene nanosheets; oxygen reduction reaction; cyclic voltammetry; lithium-oxygen battery 


\section{Introduction}

The continuous increase in demand for energy as well as global concerns over the depletion of fossil fuels has led to the exploration of high-density energy storage systems [1,2]. Among these energy systems, lithium-oxygen battery holds potential as a promising high energy density electrochemical power source anticipated to impact future battery technologies $[3,4]$. Compared to $\mathrm{LiCoO}_{2}$ intercalation cathodes in Li-ion batteries, a five-fold higher specific capacities and a four-fold higher specific energies are projected for lithium-oxygen cathodes [5]. Inspite of their high specific capacities, recent material-to-systems-level analysis of lithium-oxygen chemistry predicts importance of system-level comparable mass, volume and cost to other advanced chemistries that are in more mature states of development with low technical risk [6]. A typical lithium-oxygen battery is composed of lithium metal anode, porous carbon based cathode exposed to gaseous oxygen, and lithium ion conducting electrolyte. During discharge, lithium is oxidized at the anode and oxygen is reduced at the cathode to produce discharge products. Subsequent charging causes the decomposition of discharge products and the generation of oxygen. Although these batteries operate on a simple chemical reaction between lithium ions and oxygen molecules, there are many technical challenges that need to be overcome for realization of practical lithium-oxygen battery operating in an ambient environment. Several factors dictate the performance of these batteries, such as oxygen cathode, electrolyte composition, relative humidity, and cell design [7-14]. In particular, the material architecture of oxygen cathodes plays a key role in governing the electrochemical performance.

Abraham and Jiang [15] pioneered the lithium-oxygen battery technology. They reported cell capacity of $1410 \mathrm{mAh} / \mathrm{g}$ in pure oxygen atmosphere. Following this work, significant effort has been focused on cathode formulations [16-21], electrolyte compositions [22-25], efficient oxygen reduction catalysts [26-29], effect of moisture [30], etc. Inspite of these efforts to improve the kinetics of oxygen reduction reaction (ORR), as well as oxygen evolution reaction (OER) at the cathode, lithium-oxygen cells still exhibit significantly lower discharge capacity than the theoretical cell capacity, and high overpotential with limited cycle life. To this end, it is important to develop oxygen cathodes with a highly efficient ORR and OER catalyst that have significant impact on the desired energy densities of these cells. Recently, graphene nanosheets (GNSs) have been investigated as electrocatalyst for energy storage applications [31] because of its excellent electrical conductivity, distinct morphology, large theoretical surface area, and outstanding electro-catalytic activity. In addition, GNSs have highest reported electron mobilities and good thermal conductivity [32]. These outstanding electro-catalytic, thermal, electronic and mechanical properties make GNSs ideal material for application in ORR and OER but also to host discharge products to accommodate the large volume changes during ORR and OER processes. Recently, GNSs have been employed as oxygen cathode in fuel cells and show a higher discharge voltage under acidic condition [33]. GNSs, nitrogen-doped graphene nanosheets ( $N$-GNSs) were also exploited in non-aqueous lithium-oxygen cells as cathode material that demonstrated an exceptionally high discharge cell capacity [34-38].

In continuation of our work on a fully solid-state lithium-oxygen cells [39-42], we report here the use of GNSs, $N$-GNSs, exfoliated nitrogen-doped graphene nanosheets (Ex- $N$-GNSs), and a blend of Ex- $N$-GNSs with nitrogen-doped carbon (Hybrid 1) in a solid-state lithium-oxygen cell. In Hybrid 1, nitrogen-doped carbon [40] is a combination of nitrogen-doped Calgon activated carbon and Ketjenblack 
carbon. Since our approach to fabricate a totally solid-state lithium-oxygen battery is easily scalable, such a battery holds a great potential for applications ranging from electric cars to unmanned aerial vehicles. Although these batteries are of considerable interest, their active life is limited by the diffusion and reduction of oxygen in the cathode. The performance of the cathode in these batteries is a major limiting factor in optimizing the power output. To improve the performance of the cathode, it is of interest to investigate GNSs, $N$-GNSs, Ex- $N$-GNSs, and Hybrid 1 to enhance the oxygen reduction reaction activity. The doping of the GNSs and carbon with nitrogen atoms has drawn much attention because conjugation between the nitrogen lone-pair electrons and graphene $\pi$-systems [43-45] create nanostructures with desired properties. Importantly, the nitrogen doping of carbon materials has been shown to improve the activity of carbon for oxygen reduction [46-48]. Furthermore, the mesoporous carbon with high porosity is expected to facilitate the access of oxygen to the reaction sites inside the pores of carbon. In this work, we explore the use of mutual properties of Ex- $N$-GNSs and nitrogen-doped carbon in the cathode of a solid-state lithium-oxygen cell. The roles of porosity and surface area of GNSs, $N$-GNSs, Ex- $N$-GNSs, and Hybrid 1 on electrochemical performance of the lithium-oxygen cell are investigated. It is found that Hybrid 1 cathode delivered high discharge capacity among all GNSs based cathodes studied in this work.

\section{Results and Discussion}

The microstructure, surface area, and electro-catalytic activity of GNSs play an important role in the electrochemical performance of lithium-oxygen batteries. Scanning electron microscopy (SEM) and nitrogen adsorption-desorption isotherm at $77 \mathrm{~K}$ was employed to examine the microstructures and determine the surface area, respectively, of GNSs, $N$-GNSs, Ex- $N$-GNSs, and Hybrid 1.

\subsection{Microstructure of GNSS}

Figure 1 shows the SEM images of Ex- $N$-GNSs and nitrogen-doped carbon (nitrogen-doped Calgon activated carbon and Ketjenblack carbon). Figure 1a,b is SEM images of Ex- $N$-GNSs at lower and higher magnification. These SEM images reveal the wrinkled, porous, three-dimentional architectures with interconnected pore channels of Ex- $N$-GNSs. Very open, disorder structures with various shapes and sizes of graphene are reported [49-51]. Figure $1 \mathrm{~b}$ is the higher magnification image of Ex- $N$-GNSs shown in Figure 1a. This favorable morphology facilitates oxygen transport and provides enough voids to accommodate discharge products. Figure 1c,d is the morphology of nitrogen-doped carbon at lower and higher magnification, respectively. Figure 1c,d exhibits a fibrous, as well as flake- or plate-like structure. Energy dispersive X-ray (EDX) spectroscopic analysis conducted on Ex- $N$-GNSs revealed the nitrogen content to be 3 to 4 at wt \%, while nitrogen-doped carbon has 5 to 7 at wt \%. of nitrogen. This value of nitrogen doping is consistent with the values reported in the literature, wherein 3 to 5 at wt \% of nitrogen in N-doped, reduced graphene were reported [49,50]. These starting materials, nitrogen-doped carbon and Ex- $N$-GNSs, were used to prepare Hybrid 1. 


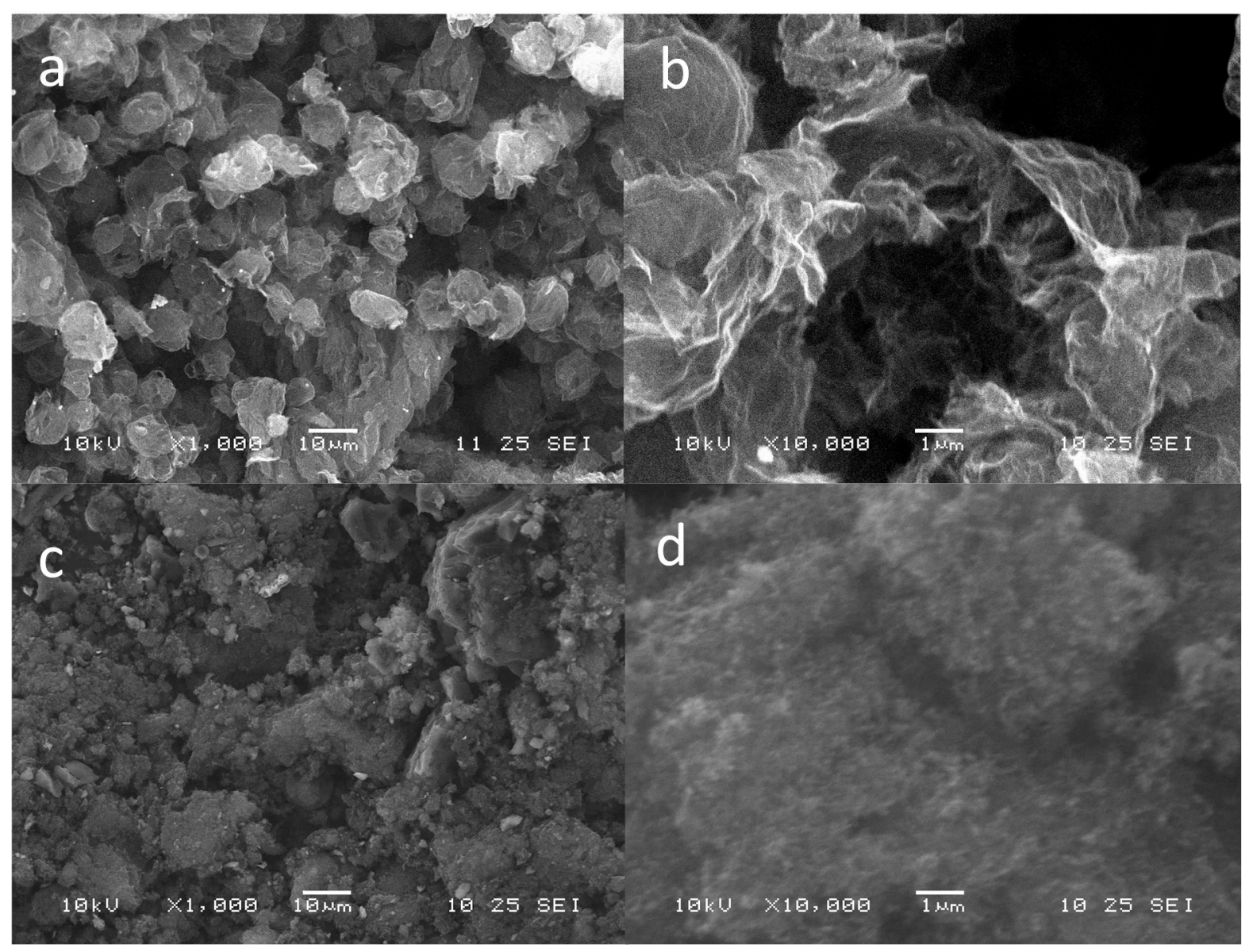

Figure 1. SEM images of Ex- $N$-GNSs at (a) lower magnification (b) higher magnification. SEM images of nitrogen-doped carbon at (c) lower magnification and (d) higher magnification.

\subsection{Nitrogen Adsorption-Desorption Isotherm}

A typical nitrogen adsorption-desorption isotherm at $77 \mathrm{~K}$ for Ex- $N-G N S s$ is shown in Figure 2 and for Hybrid 1 in Figure S1 (Supplementary Information). Isotherm shows adsorption hysteresis indicating the presence of mesopores. The Brunauer-Emmett-Teller (BET) surface area, pore volume and pore size of GNSs, $N$-GNSs, Ex- $N$-GNSs, and Hybrid 1 are presented in Table 1. The remarkable nitrogen uptake above the relative pressure ratio of 0.40 has been observed in BET isotherms and is due to the condensation of nitrogen in porous GNSs. The pore size distribution of Ex- $N$-GNSs is shown in Figure $2 \mathrm{~b}$, and indicates a wide variation in pore size. Such high porosity helps to improve the cell capacity of lithium-oxygen cell, as described in the oxygen diffusion model that predicts the cathode pore radius is reflective of the distribution of the discharge products like lithium peroxide formed in the cathode during the cell discharge [52]. 


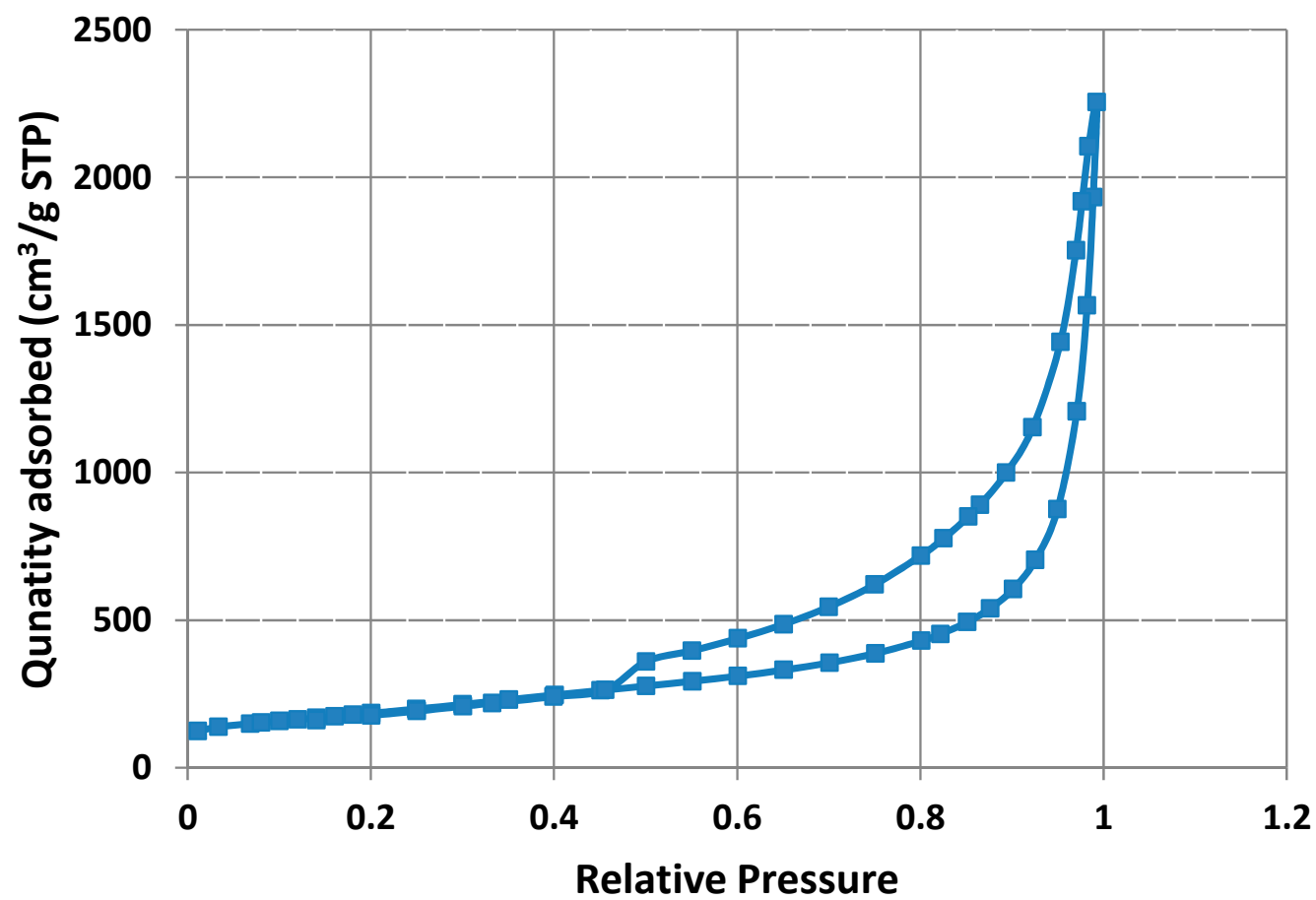

(a)

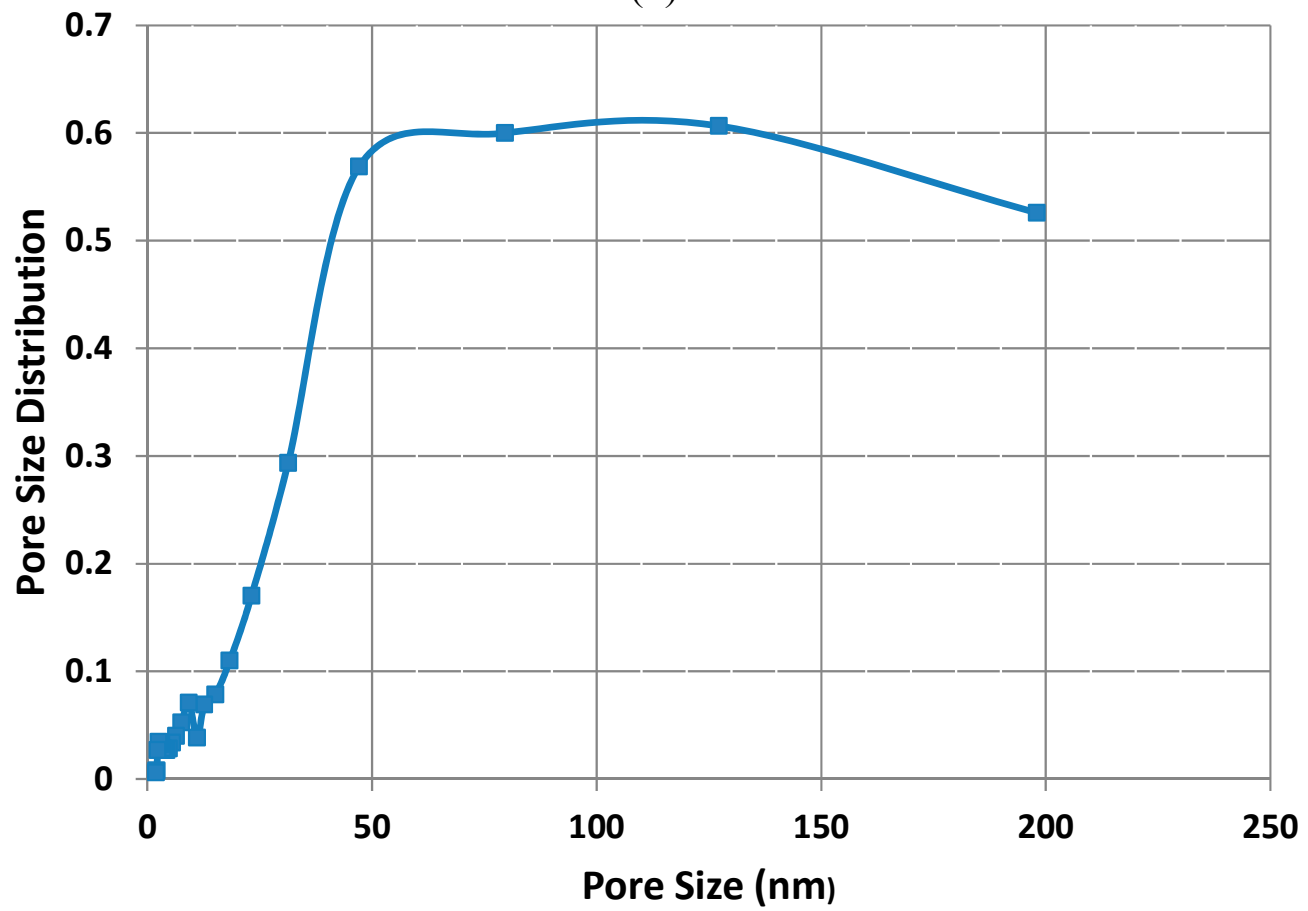

(b)

Figure 2. (a) Typical $\mathrm{N}_{2}$ adsorption-desorption isotherm and (b) corresponding pore size distribution for the Ex- $N$-GNSs. 
Table 1. Physical and electrochemical properties of various grapheme-based materials.

\begin{tabular}{cccccc}
\hline Cathode Materials & N-C Blend & GNSs & $N$-GNSs & Ex- $N$-GNSs & Hybrid 1 \\
\hline Surface Area $\left(\mathrm{m}^{2} / \mathrm{g}\right)$ & 1385 & 482 & 581.6 & 686.6 & 900 \\
\hline Pore volume $\left(\mathrm{cm}^{3} / \mathrm{g}\right)$ & 1.8 & 1.3 & 1.72 & 1.86 & 1.9 \\
\hline $\begin{array}{c}\text { Average Pore } \\
\text { Size }(\mathrm{nm})\end{array}$ & 6.3 & 10.96 & 11.18 & 11.36 & 11.86 \\
\hline Porosity (\%) & 42 & 8.76 & 21.88 & 24.5 & 30 \\
\hline $\begin{array}{c}\text { Oxygen Reduction } \\
\text { Potential (V vs. SCE) }\end{array}$ & -0.45 & -0.389 & -0.466 & -0.434 & -0.596 \\
\hline $\begin{array}{c}\text { Open Circuit } \\
\text { voltage (V) }\end{array}$ & 3.18 & 3.4 & 3.6 & 3.5 & 3.25 \\
\hline $\begin{array}{c}\text { Discharge cell } \\
\text { capacity (mAh) }\end{array}$ & 1.44 & 1.98 & 2.75 & 5.87 & 9.82 \\
\hline $\begin{array}{c}\text { Specific Capacity (mAh/g } \\
\text { Graphene and/or Carbon) }\end{array}$ & 167 & 330 & 456.8 & 1028 & 1687.3 \\
\hline
\end{tabular}

\subsection{Cyclic Voltammetry}

The electro-catalytic ability of GNSs, $N$-GNSs, Ex- $N$-GNSs and Hybrid 1 in oxygen saturated aqueous solution of $0.1 \mathrm{M} \mathrm{KOH}$ was evaluated by cyclic voltammetry (CV). In this work, CV measurements were performed to check the electro-catalytic ability for its selection as cathode materials to fabricate lithium-oxygen cell. Figure 3 shows typical cyclic voltammograms for Ex- $N$-GNSs and Hybrid 1 with well-defined ORR peaks ( $\mathrm{C} 1$ and $\mathrm{C} 2$ ), as well as the broad and weak anodic oxidative peaks (A1 and A2) in oxygen saturated $0.1 \mathrm{M} \mathrm{KOH}$. CV curves for GNSs and $N$-GNSs are presented in Figure S2. Well defined ORR peaks at around $-0.434 \mathrm{~V}$ and $-0.596 \mathrm{~V}$ vs. the saturated calomel electrode (SCE) were observed for Ex- $N$-GNSs and Hybrid 1, respectively. The catalytic reduction current density for Ex- $N$-GNSs and Hybrid 1 were found to be 0.97 and $1.2 \mathrm{~mA} / \mathrm{cm}^{2}$, respectively. Compared to Ex- $N$-GNSs, Hybrid 1 exhibits higher magnitude difference in catalytic reduction current density at the potential along the negative scan. It is observed from Figure 3 that the total cathodic current density for Ex- $N$-GNSs and Hybrid 1 are 2.78 and $3.55 \mathrm{~mA} / \mathrm{cm}^{2}$, respectively. The observed higher capacitive current is due to the surface defects on the graphene. Such an analogous increase in capacitive current values is reported and it is stated that the surface defects lead to a significant increase in capacitance values and surface reaction kinetics in carbon nanomaterials [53,54]. In our work, a slightly higher capacitance is observed for Hybrid 1 in oxygen saturated $\mathrm{KOH}$ solution than in nitrogen saturated $\mathrm{KOH}$, but the ratio of capacitance is reasonable. Hybrid 1 electrode is a blend of Ex-N-GNSs and nitrogen-doped carbon powder. Nitrogen-doping and exfoliation of graphene creates defects on the edges and walls of graphene. These defects and structural modification of Ex- $N$-GNSs in Hybrid 1 are beneficial for adsorption of oxygen molecules, which leads to the modification of electronic properties of Hybrid 1 . Thus, the slight higher capacitance observed in Hybrid 1 electrode in oxygen saturated $\mathrm{KOH}$ may be due to the adsorption of oxygen and higher conductivity in oxygen saturated $\mathrm{KOH}$ solutions. In addition, graphene lattice orientation and various functional groups on the surface of Ex- $N$-GNSs may also help increase the current in oxygen saturated $\mathrm{KOH}$ solution. Additional studies will be required to understand the origin and reaction kinetics in graphene nanomaterials. In addition to ORR peaks, Figure 3 also shows 
broad anodic oxidative peaks (A1 and A2) around $0.548 \mathrm{~V}$ and $0.458 \mathrm{~V}$ for Ex- $N$-GNSs and Hybrid 1, respectively. The origin of these anodic peaks (A1 and A2) is not clear, but they could be arising from the support electrode. Compared to Ex- $N$-GNSs, Hybrid 1 exhibits higher magnitude difference in reduction current at potential along the negative scan direction, indicating stronger electro-catalytic activity.

It is observed from Figure 3 that the cathodic peak is significantly stronger than the anodic peak. The total cathodic and anodic current densities for Ex- $N-\mathrm{GNSs}$ are 2.78 and $2.24 \mathrm{~mA} / \mathrm{cm}^{2}$, respectively. For Hybrid 1, the total cathodic and anodic current densities are 3.55 and $1.85 \mathrm{~mA} / \mathrm{cm}^{2}$, respectively. There is asymmetry in the cathodic and anodic peak locations and intensities. This asymmetry may be due to kinetic hindrance to the transport of $\mathrm{O}_{2}$ and asymmetric activation energy for the involved reactions. In spite of the nature of these peak locations, Figure 3 clearly demonstrates the electro-catalytic activity for Ex- $N$-GNSs and Hybrid 1 cathode materials towards oxygen reduction.

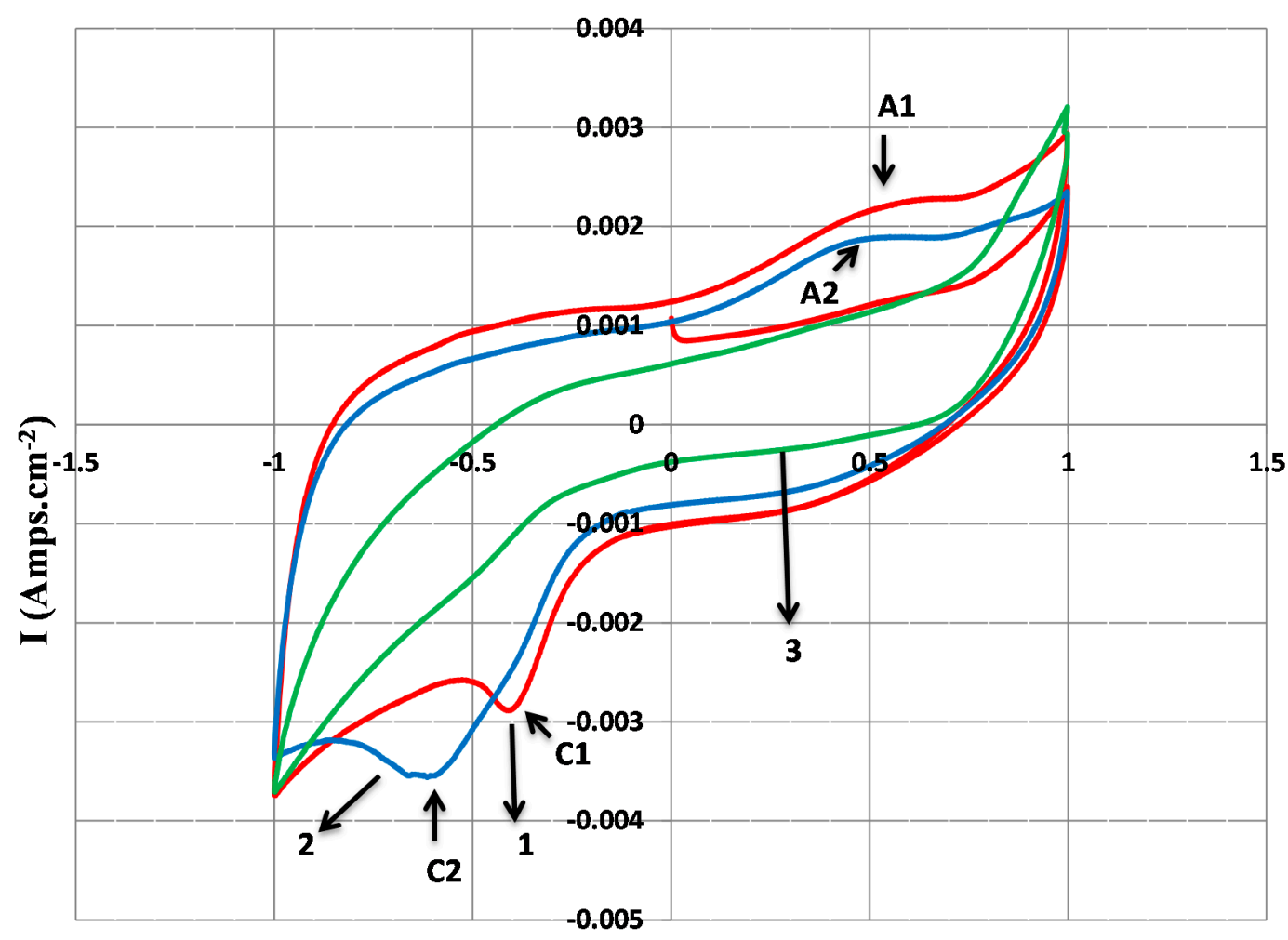

E (Volts)

Figure 3. Typical CV curves of (1) Ex- $N$-GNSs and (2) Hybrid 1 in oxygen saturated $0.1 \mathrm{M} \mathrm{KOH}$; and (3) Hybrid 1 in nitrogen saturated $0.1 \mathrm{M} \mathrm{KOH}$ at $25^{\circ} \mathrm{C}$ at scan rate of $5 \mathrm{mV} \cdot \mathrm{min}^{-1}$.

\subsection{Discharge Profile of Cathodes in Lithium-Oxygen Battery}

Based on the high surface area, porous structure as well as electro-catalytic activity towards oxygen reduction of GNSs, $N$-GNSs, Ex- $N$-GNSs, and Hybrid 1, solid-state lithium-oxygen cells with $1 \mathrm{~cm}^{2}$ active area were fabricated. A schematic of cell configuration is shown in Figure 4. A lithium anode and graphene based cathode is separated by a solid electrolyte laminate. The solid electrolyte laminate is comprised of LAGP solid electrolyte and two polymer-ceramic (PC) membranes, prepared from dried polyethylene oxide (PEO), $\mathrm{LiBETI}$ salt, and $\mathrm{Li}_{2} \mathrm{O}$, as reported in literature [39]. The cathode side of the 
cell has perforations to access oxygen. Lithium metal anode was coupled to the oxygen cathode through the solid electrolyte laminate, described in detail our previous work [39]. A solid-state cell, such as the one investigated in this effort, is subjected to a conditioning cycle using a small discharge and charge current of $0.05 \mathrm{~mA}$. This conditioning of lithium-oxygen cell is carried at $75^{\circ} \mathrm{C}$. During this conditioning process, the PC membrane becomes soft. The PC membrane bonds the graphene based cathode to one side of LAGP and other PC membrane bonds the other side of LAGP electrolyte to lithium anode. It is observed that the PC membrane reduces the impedance of the cell and passivates the lithium surface from reacting with LAGP.

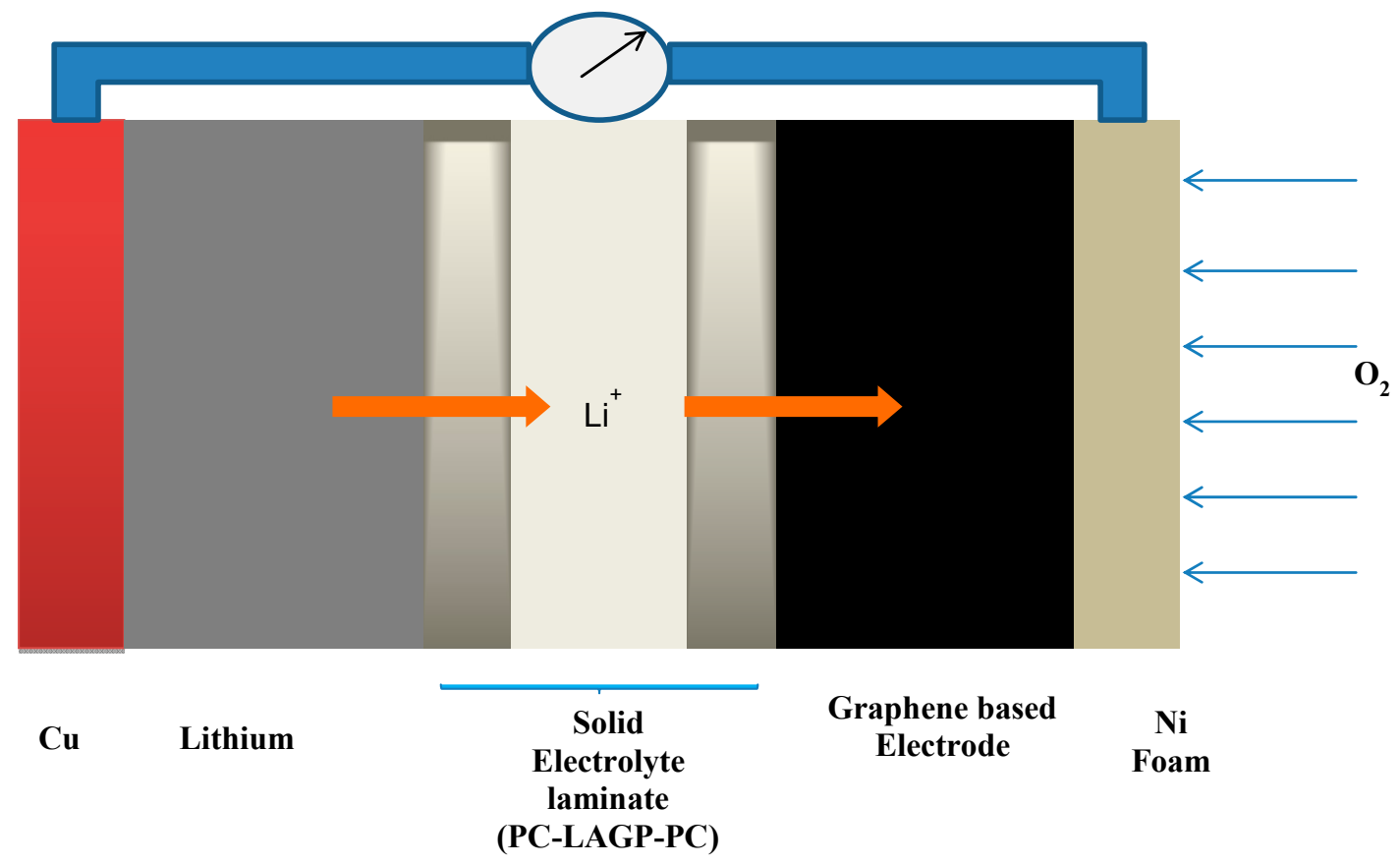

Figure 4. A schematic of the lithium-oxygen cell and its components. Solid electrolyte laminate is composed of PC-LAGP-PC membrane.

The solid electrolyte laminate provides high ionic conductivity for transport of lithium ions from lithium anode to oxygen cathode [55]. In addition, the electrolyte laminate improves lithium-electrolyte interfacial stability. No liquid electrolyte was used in this work. LAGP was used as solid electrolyte. LAGP is not commercially available and hence was prepared by conventional solid-state reaction technique reported in the literature [56,57].

The electrochemical performance of GNSs, $N$-GNSs, Ex- $N$-GNSs, and Hybrid 1 was evaluated as cathodes in lithium-oxygen cell in oxygen atmosphere. Figure 5 shows the first discharge profiles of the lithium-oxygen cells with GNSs, $N$-GNSs, Ex- $N$-GNSs, and Hybrid 1 cathodes using discharge current of $0.2 \mathrm{~mA}$ at $75^{\circ} \mathrm{C}$. Cell with Hybrid 1 as cathode delivers five times higher cell capacity ( $9.82 \mathrm{mAh}$ ) than the cell with cathode composed of GNSs. Cells composed of GNSs, $N$-GNSs, and Ex- $N$-GNSs as cathodes delivered 1.98, 2.75 and 5.87 mAh discharge capacities, respectively. It is observed from Table 1 that there is an incremental increase in discharge cell capacity from the cell composed of GNSs to the Hybrid 1. In our previous work on cells composed of carbon blend (mixture of Ketjenblack and Calgon activated carbon) and nitrogen-doped carbon blend under identical conditions delivered 0.7 and 1.44 mAh cell capacity [40]. Thus, cell capacity enhancement is more than two times when the carbon 
blend is replaced by graphene in the cathode of lithium-oxygen cells; while nitrogen doping in GNSs and exfoliation of nanosheets has further improved the cell capacity by more than two times. To maintain consistency with the literature, the specific capacities, normalized with the weight of the graphene and/or carbon present in cathode material, for GNSs, $N$-GNSs, Ex- $N$-GNSs, and Hybrid 1 cathodes were evaluated and presented in Table 1. Cell based on Hybrid 1 exhibits highest discharge cell capacity $(9.82 \mathrm{mAh})$ and specific capacity $(1687.3 \mathrm{mAh} / \mathrm{g})$ among all cathodes studied in this work. It is observed from Table 1 that Hybrid 1 has larger pore size than the $\mathrm{N}-\mathrm{C}$ blend. A larger pore size improves oxygen diffusion into the cathode matrix, facilitating oxygen reduction inside the surface of the pores, and yields higher discharge capacity. Our results are consistent with those of Ding et al., who reported the influence of carbon pore size on the discharge capacity of lithium-oxygen battery [58]. It is also reported that the uniformity of the pore size plays an important role in determining the electrochemical performance of these cells [59]. Compared to $\mathrm{N}-\mathrm{C}$ blend cathode, Hybrid 1 has a lower surface area and porosity but still exhibits higher discharge cell capacity (Table 1). This may be attributed to difference in the microstructure of these cathode materials (Figure 1), larger pore size (Table 1), as well as higher active/effective electrochemical surface area of Hybrid 1 cathode than $\mathrm{N}-\mathrm{C}$ blend cathode. These results are consistent with those of Yang et al. [60] on cathode fabricated with low surface area and larger pore size carbon, and our earlier work [40,42] on cathode fabricated with carbon, N-C blend and LAGP that exhibits enhanced discharge cell capacity. Sun et al. reported the influence of microstructure of graphene and Vulcan XC-72 carbon cathode on the discharge capacity of lithium-oxygen battery [61]. It is also reported that the zigzag edges of graphene nanosheets have unique edge state's electronic structure, offering special chemical reactivity and serve as active sites for the electrochemical reaction of oxygen $[62,63]$. The cathode material, Hybrid 1 was prepared by mixing nitrogen-doped carbon powder and Ex- $N$-GNSs. Our rationale for using the nitrogen-doped carbon was to take advantage of the high surface area $\left(1385 \mathrm{~m}^{2} / \mathrm{g}\right)$ and high porosity (42\%) of nitrogen-doped carbon [40]. Addition of nitrogen-doped carbon to Ex- $N$-GNSs (surface area of $686.6 \mathrm{~m}^{2} / \mathrm{g}$ and porosity of $24.5 \%$ ) increases its porosity to $30 \%$ and surface area to $900 \mathrm{~m}^{2} / \mathrm{g}$ in Hybrid 1 (Table 1). High porosity facilitates more efficient access of gaseous $\mathrm{O}_{2}$ molecules to the reaction sites inside the pores of Hybrid 1. A high surface area is desirable to enhance the oxygen reduction activity on catalytic reaction sites. In this work, Ex- $N$-GNSs show superior electro-catalytic activity for oxygen reduction reaction. Thus, combination of nitrogen-doped carbon and Ex- $N$-GNSs in the Hybrid 1 affords high electro-catalytic sites to catalyze the discharge reaction, leading to higher discharge cell capacity. In order to check repeatability of the cell capacity of these graphene based cathodes, the measurements were carried out on two sets of cathode material. Both cathode materials delivered similar discharge capacity. In addition, a higher porosity of cathodes increases oxygen diffusivity in the cathode and accumulates the reaction products that help to improve the cell capacity. It is reported that the pores of different sizes are filled with discharge products at different rate [64]. A gradual decrease in cell discharge from 2.8 to $2.4 \mathrm{~V}$ is also observed in Figure 5 for Hybrid 1. A sharp cell discharge is observed at around $2.1 \mathrm{~V}$ for $N$-GNSs and Ex- $N$-GNSs; while GNSs show a sharp cell discharge at around 2.5 V. It is noticed from Figure 5 that, although open circuit voltage (OCV) of all cells are high, there is a significant potential drop during the initial stage of discharge. This potential drop is due to both an activation barrier of cathode chemistry that includes kinetics, and series resistances between various cell components. 


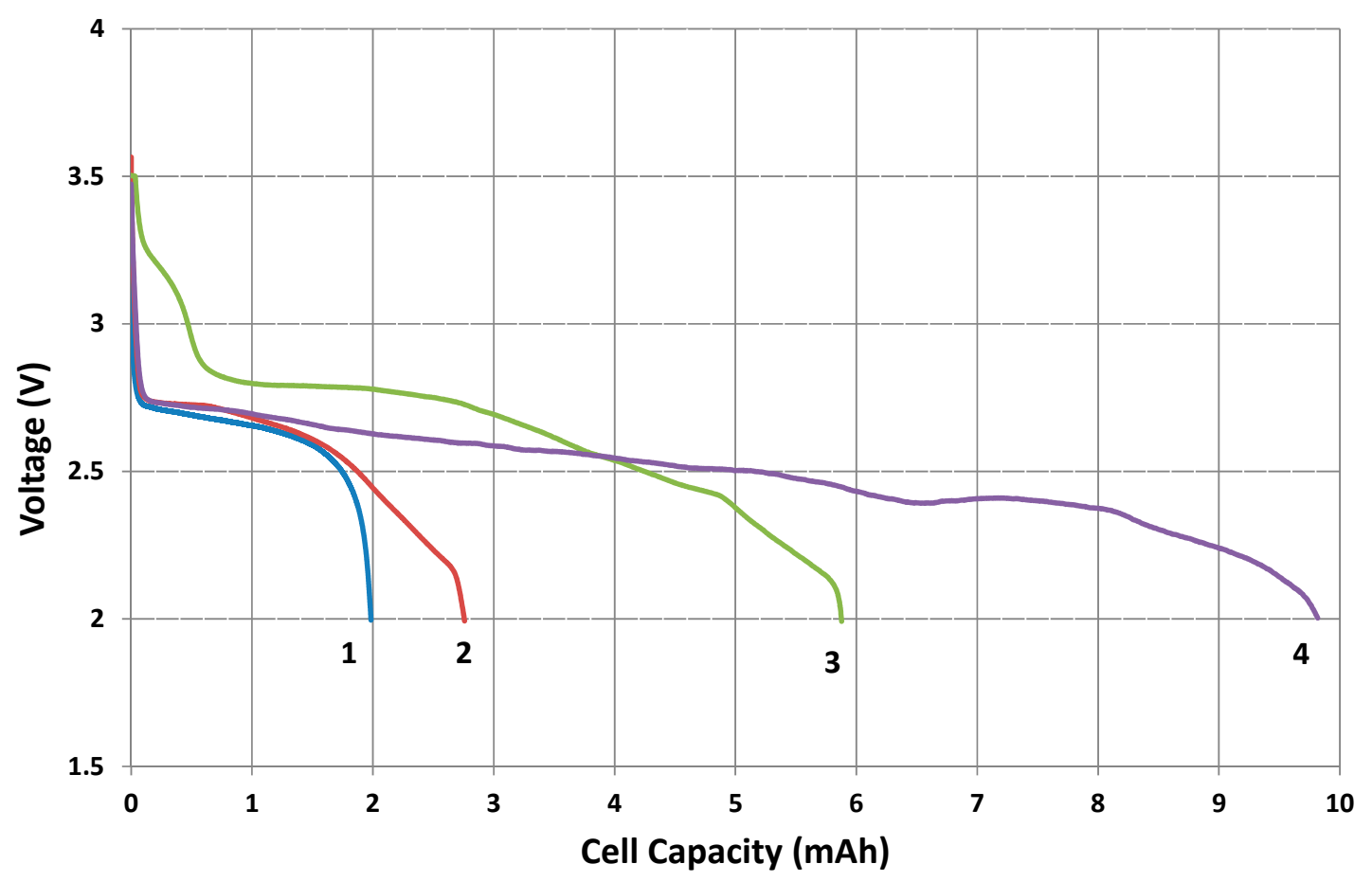

Figure 5. Discharge profiles for a lithium-oxygen cells at $75^{\circ} \mathrm{C}$ using (1) GNSs; (2) $N$-GNSs; (3) Ex- $N$-GNSs and (4) Hybrid 1 as cathode in oxygen atmosphere.

\subsection{Electrochemical Impedance Spectroscopy of Cathodes}

Electrochemical impedance spectroscopy (EIS) was used to investigate the electrochemical performance of cathode in the lithium-oxygen cell. The impedance of the lithium-oxygen cell was measured before and after discharge. Typical Nyquist plots after discharge in the frequency range from $1 \mathrm{~Hz}$ to $1 \mathrm{MHz}$ for GNSs, $N$-GNSs, Ex- $N$-GNSs, and Hybrid 1 are shown in Figure 6. A simple Randall equivalent circuit model was used to describe the observed impedance spectrum. All plots exhibit a semicircle with tail. The high frequency intercept on the $Z$ ' axis corresponds to the resistance of the cell which includes contributions from the electrodes, electrolyte, and contact resistance. The numerical value of width of semicircle on the Z' axis corresponds to the charge transfer resistances. A tail in the low frequency region represents the characteristics of a diffusion controlled process due to the diffusion of lithium ions and oxygen in the cathode [65]. Nyquist plots before the discharge (Figure S3) exhibit a lower charge-transfer resistance for Hybrid 1, pointing to faster charge-transfer kinetics. From the Nyquist plots obtained after discharge, the values of charge-transfer resistance were determined to be 310, 198, 175, and $263 \Omega$ for the GNSs, $N$-GNSs, Ex-NGSs, and Hybrid 1, respectively. EIS analysis suggests that the major contribution to the cell resistance is the charge-transfer resistance. Thus, the nitrogen doping and exfoliation of graphene nanosheets reduces charge-transfer resistance and improves the ORR as evidenced from Figures 6 and S3. In addition, at a discharge current of $0.2 \mathrm{~mA}$, there is an increase in cell capacity of lithium-oxygen cell prepared with $N$-GNSs, Ex- $N$-GNSs, and Hybrid 1 relative to the capacity of cells with GNSs. Both of these observations lead to the conclusion that nitrogen doping and exfoliation of graphene/carbon helps improve the kinetics of ORR in the oxygen cathode. EIS results combined with $\mathrm{CV}$ experiments lead to the conclusion that the electro-catalytic activity towards the ORR progressively increases for $N$-GNSs, Ex-NGSs, and Hybrid 1 in oxygen cathode. 


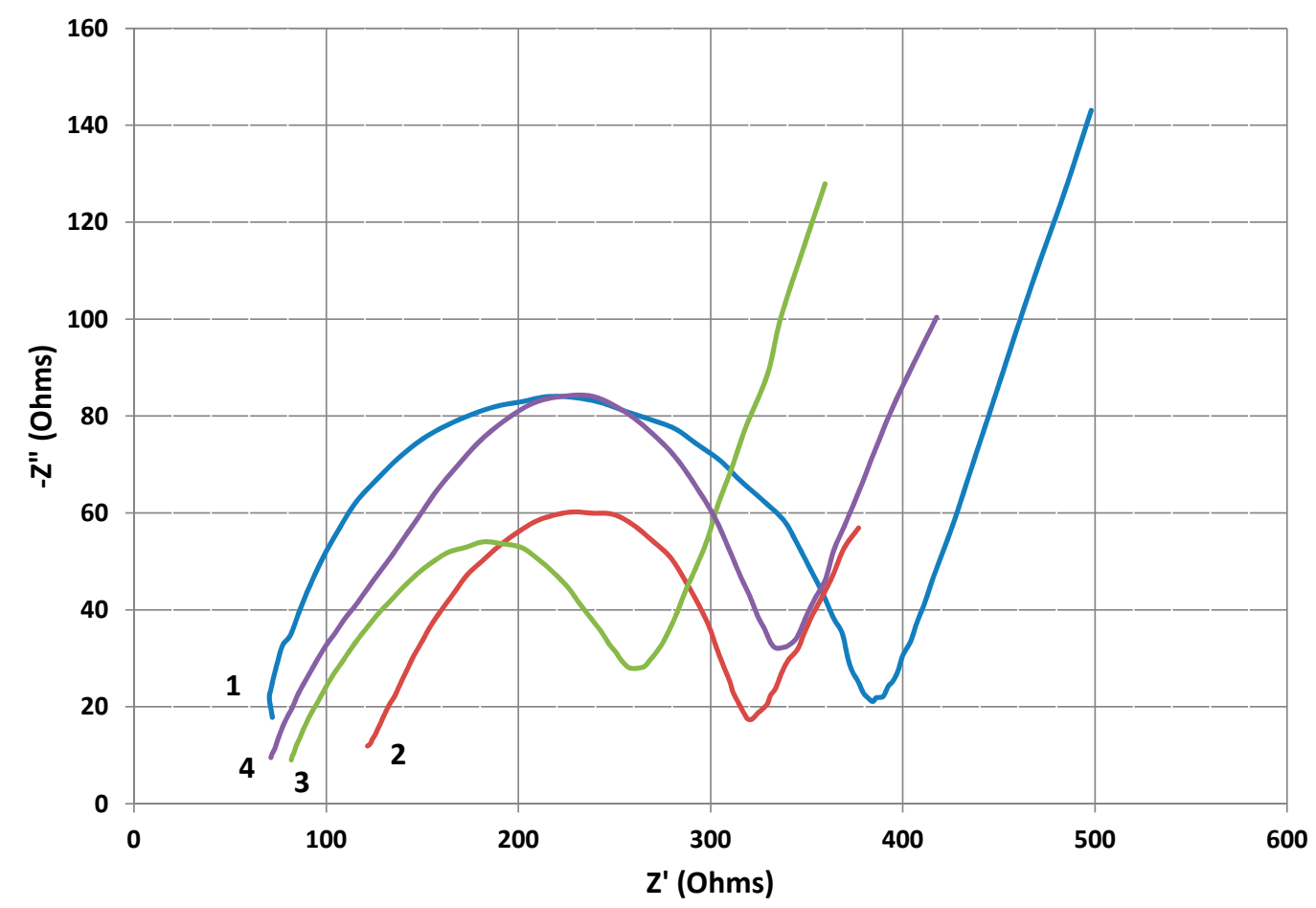

Figure 6. Nyquist plots of lithium-oxygen cell after discharge at $75{ }^{\circ} \mathrm{C}$ using (1) GNSs; (2) $N$-GNSs; (3) Ex-N-GNSs and (4) Hybrid 1 as cathode.

\section{Experimental Section}

\subsection{Preparation of Cathode Material}

Commercially available GNSs (Angstron Materials, Inc., Dayton, OH, USA) were heated in a vacuum oven at $250{ }^{\circ} \mathrm{C}$ to remove any residual surfactants. These thermally treated GNSs were used for preparation of $N$-GNSs and Ex- $N$-GNSs. The procedure described in the literature [31] was used for preparing $N$-GNSs and Ex- $N$-GNSs. In addition, Hybrid 1 was prepared by mixing nitrogen-doped carbon (mixture of nitrogen-doped Calgon activated carbon and Ketjenblack carbon in 40:60 wt \% ratio) and Ex- $N$-GNSs in 50:50 wt \% ratio. These powders of GNSs, $N$-GNSs, Ex- $N$-GNSs and Hybrid 1 were used to fabricate oxygen cathodes.

\subsection{Characterization of Cathode Materials}

A scanning electron microscope (JEOL JSM-6060) equipped with an energy dispersive X-ray (EDX) spectroscopy assembly was used to investigate the morphologies of the specimens. The surface areas of the specimens were determined by nitrogen adsorption/desorption measurements at $77 \mathrm{~K}$ (Micromeritis ASAP 2020). The porosity of cathode material was characterized by a gas pycnometer (Micromeritis, Accu Pyc II 1340). CV and galvanostatic charge-discharge measurements of the specimens were conducted using a computer controlled VersaSTAT 4 (Princeton Applied Research) electrochemical workstation. $\mathrm{CV}$ measurements were performed in a standard three-electrode cell configuration using $0.1 \mathrm{M} \mathrm{KOH}$ as the electrolyte at $25^{\circ} \mathrm{C}$ with a scan rate of $5 \mathrm{mV} \cdot \mathrm{min}^{-1}$. The working electrode for $\mathrm{CV}$ measurement was prepared by applying a paste of specimen and Nafion (tetrafluoroethylene based fluoropolymer-copolymer) on the tip of a graphite rod. Pt wire and SCE were used as counter and reference electrodes, respectively. 
All potentials were measured with respect to SCE. EIS measurements on the lithium-oxygen cells were conducted over a frequency range of $1 \mathrm{~Hz}$ to $1 \mathrm{MHz}$ before and after discharge/charge measurements. All electrochemical tests on these cells were carried under an oxygen atmosphere.

\subsection{Fabrication and Electrochemical Performance of Cathode}

Each of these powders, GNSs, $N$-GNSs, Ex- $N$-GNSs, and Hybrid 1, were mixed and dispersed in $\mathrm{N}$-methyl-2-pyrrolidone (NMP) by probe sonication to obtain a viscous slurry. A nickel foam was then suspended in this solution with sonication for $90 \mathrm{~min}$. This process was carried to load cathode materials in the open voids of nickel foam. Subsequently, the cathode specimen was dried overnight at $120{ }^{\circ} \mathrm{C}$ under vacuum. A solid-state lithium-oxygen cell with a $1 \mathrm{~cm}^{2}$ area was fabricated using a Swagelok type cell in a dry room with controlled moisture content. Nickel foam with GNSs/ $N$-GNSs/Ex- $N$-GNSs/Hybrid 1 was used as working cathodes, along with lithium metal as anode and LAGP as solid electrolyte. The lithium-oxygen cells were discharged with constant discharge current of $0.2 \mathrm{~mA}$. EIS measurements on the lithium-oxygen cells were conducted over a frequency range of $1 \mathrm{~Hz}$ to $1 \mathrm{MHz}$ before and after discharge/charge measurements. All electrochemical tests on these cells were carried out under an oxygen atmosphere.

\section{Conclusions}

In conclusion, this work demonstrates excellent cell performance of lithium-oxygen cell with cathode formulation based on GNSs. Cell composed of Hybrid 1 cathode delivers $9.82 \mathrm{mAh}$ discharge cell capacity and $1687.3 \mathrm{mAh} / \mathrm{g}$ specific capacity. By comparison to the GNSs with a discharge cell capacity of $1.98 \mathrm{mAh}$ and a specific capacity of $330 \mathrm{mAh} / \mathrm{g}$, the Hybrid 1 studied here exhibited five times the enhancement in the cell capacity. This enhancement is more than an order of magnitude, when the discharge cell capacity of Hybrid 1 is compared to carbon blend [40] reported in our earlier work. The improvement in the cell capacity is attributed to the synergistic effect of microstructure, active/effective electrochemical surface area, pore size, percent porosity and electro-catalytic activity of Ex- $N$-GNSs and nitrogen-doped carbon blend used in Hybrid 1 cathode. This work highlights the importance of novel cathode architecture and opens up a promising approach to develop highly efficient oxygen electrodes for lithium-oxygen cells.

\section{Supplementary Materials}

Supplementary materials can be found at http://www.mdpi.com/ 2311-5629/1/01/27/s1.

\section{Acknowledgments}

This research was supported by the Air Force Research Laboratory, Wright-Patterson Air Force Base, $\mathrm{OH}$, USA.

\section{Author Contributions}

Both authors contributed to design of the experiments, analysis of results and writing of the paper. 


\section{Conflicts of Interest}

The authors declare no conflict of interest.

\section{References}

1. Larcher, D.; Tarascon, J.M. Towards greener and more sustainable batteries for electrical energy storage. Nat. Chem. 2015, 7, 19-29.

2. Van Noorden, R. A better battery. Nature 2014, 507, 26-28.

3. Bruce, P.G.; Freunberger, S.A.; Hardwick, L.J.; Tarascon, J.M. Li-O 2 and Li-S batteries with high energy storage. Nat. Mater. 2012, 1, 19-29.

4. Linden, D. Handbook of Batteries and Fuel Cells, 2nd ed.; McGraw-Hill: New York, NY, USA, 1984.

5. Lu, Y.-C.; Gasteiger, H.A.; Parent, M.C.; Chiloyan, V.; Shao-Horn, Y. The influence of catalysts on discharge and charge voltages of rechargeable Li-oxygen batteries. Electrochemical. Solid State Lett. 2010, 13, A69-A72.

6. Gallagher, K.G.; Goebel, S.; Greszler, T.; Mathias, M.; Oelerich, W.; Eroglu, D.; Srinivasan, V. Quantifying the promise of lithium-air batteries for electric vehicles. Energy Environ. Sci. 2014, 7 , $1555-1563$.

7. Luntz, A.C.; McCloskey, B.D. Nonaqueous Li-air batteries: A status report. Chem. Rev. 2014, 114, $11721-11750$.

8. Girishkumar, G.; McCloskey, B.; Luntz, A.C.; Swanson, S.D.; Wilcke, W.J. Lithium-air battery: Promise and challenges. J. Phys. Chem. Lett. 2010, 1, 2193-2203.

9. Lu, J.; Park, J.-B.; Sun, Y.-K.; Wu, F.; Amine, K. Aprotic and aqueous Li-O 2 batteries. Chem. Rev. 2014, 114, 5611-5640.

10. Zhang, T.; Zhou, H.B. A reversible long-life lithium-air battery in ambient air. Nat. Commun. 2013, doi:10.1038/ncomms2855.

11. Oh, D.; Qi, J.; Lu, Y.C.; Zhang, Y.; Shao-Horn, Y.; Belcher, A.M. Biologically enhanced cathode design for improved capacity and cycle life for lithium-oxygen batteries. Nat. Commun. 2013, doi:10.1038/ncomms3756.

12. Lim, H.D.; Song, H.; Kim, J.; Gwon, H.; Bae, Y.; Park, K.Y.; Hong, J.; Kim, H.; Kim, T.; Kim, Y.H.; et al. Superior rechargeability and efficiency of lithium-oxygen batteries: Hierarchical air electrode architecture combined with a soluble catalyst. Angew. Chem. Int. Ed. 2014, 53, 39263931.

13. Grande, L.; Paillard, E.; Hassoun, J.; Park, J.-B.; Lee, Y.-J.; Sun, Y.-K.; Passerini, S.; Scrosati, B. The lithium/air battery: Still an emerging system or a practical reality? Adv. Mater. 2015, 27, 784-800.

14. Balaish, M.; Peled, E.; Golodnitsky, D.; Ein-Eli, Y. Liquid-free lithium-oxygen batteries. Angew. Chem. Int. Ed. 2015, 54, 436-440.

15. Abraham, K.M.; Jiang, Z. A polymer electrolyte-based rechargeable lithium/oxygen battery. J. Electrochem. Soc. 1996, 143, 1-5.

16. Zhang, S.S.; Foster, D.; Read, J. Discharge characteristics of a non-aqueous electrolyte Li/ $\mathrm{O}_{2}$ battery. J. Power Sources 2010, 195, 1235-1240. 
17. Beattie, S.D.; Manolescu, D.M.; Blair, S.L. High-capacity lithium-air cathodes. J. Electrochem. Soc. 2009, 156, A44-A47.

18. Wang, D.; Xiao, J.; Xu, W.; Zhang, J.-G. High capacity pouch-type Li-air batteries. J. Electrochem. Soc. 2010, 157, A760-A764.

19. Eswaran, M.; Munichandraiah, N.; Scalon, L.G. High capacity Li-O 2 cell and electrochemical impedance spectroscopy. Electrochem. Solid State Lett. 2010, 13, A121-A124.

20. Trahey, L.; Johnson, C.S.; Vaughey, J.T.; Kang, S.H.; Hardwick, L.J.; Freunberger, S.A.; Bruce, P.G.; Thackeray, M.M. Activated lithium-metal-oxides as catalytic electrodes for $\mathrm{Li}-\mathrm{O}_{2}$ cells. Electrochem. Solid State Lett. 2011, 14, A64-A66.

21. Shui, J.; Du, F.; Xue, C.; Li, Q.; Dai, L. Vertically aligned N-doped coral-like carbon fiber arrays as efficient air electrodes for high-performance nonaqueous $\mathrm{Li}^{-} \mathrm{O}_{2}$ batteries. ACS Nano 2014, 8, 3015-3022.

22. Lu, Y.C.; Xu, Z.; Gasteiger, H.A.; Chen, S.; Hamad-Schifferli, K.; Shao-Horn, Y. Platinum-gold nanoparticles: A highly active bifunctional electrocatalyst for rechargeable lithium-air batteries. J. Am. Chem. Soc. 2010, 132, 12170-12171.

23. Ren, X.; Zhang, S.S.; Tran, D.T.; Read, J. Oxygen reduction reaction catalyst on lithium/air battery discharge performance. J. Mater. Chem. 2011, 21, 10118-10125.

24. Nasybulin, E.; Xu, W.; Engelhard, M.H.; Nie, Z., Burton, S.D.; Cosimbescu, L.; Gross, M.E.; Zhang, J.-G. Effect of electrolyte salts on the performance of $\mathrm{Li}^{-\mathrm{O}_{2}}$ batteries. J. Phys. Chem. C 2013, 117, 2635-2645.

25. Elia, G.A.; Hassoun, J.; Kwak, W.-J.; Sun, Y.-K.; Scrosati, B.; Mueller, F.; Bresser, D.; Passerini, S.; Oberhumer, P.; Tsiouvara, N.; et al. An advanced lithium-air battery exploiting an ionic liquidbased electrolyte. Nano Lett. 2014, 14, 6572-6577.

26. Laoire, C.O.; Mukerjee, S.; Plichta, E.J.; Hendrickson M.A.; Abraham, K.M. Influence of nonaqueous solvents on the electrochemistry of oxygen in the rechargeable lithium-air battery. J. Phys. Chem. C 2010, $1149178-9186$.

27. Freunberger, S.A.; Chen, Y.; Peng, Z.; Griffin, J.M.; Hardwick, L.J.; Barde, F.; Novak, P.; Bruce, P.G. Reactions in the rechargeable lithium- $\mathrm{O}_{2}$ battery with alkyl carbonate electrolytes. J. Am. Chem. Soc. 2011, 133, 8040-8047.

28. Park, H.W.; Lee, D.U.; Nazar, L.F.; Chen, Z. Oxygen reduction reaction using $\mathrm{MnO}_{2}$ nanotubes/ nitrogen-doped exfoliated graphene hybrid catalyst for $\mathrm{Li}^{-\mathrm{O}_{2}}$ battery applications. J. Electrochem. Soc. 2013, 160, A344-A350.

29. Safari, M.; Adams, B.D.; Nazar, L.F. Kinetics of oxygen reduction in aprotic $\mathrm{Li}-\mathrm{O}_{2}$ cells: A modelbased study. J. Phys. Chem. Lett. 2014, 5, 3486-3491.

30. Meini, S.; Piana, M.; Tsiouvaras, N.; Garsuch, A.; Gasteiger, H.A. The effect of water on the discharge capacity of a non-catalyzed carbon cathode for $\mathrm{Li}-\mathrm{O}_{2}$ batteries. Electrochem. Solid State Lett. 2012, 15, A45-A48.

31. Kim, H.; Lim, H.D.; Kim, J. Kang, K. Graphene for advanced Li/S and Li/air batteries. J. Mater. Chem. A 2014, 2, 33-47.

32. Li, Y.; Wang, J.; Li, X.; Geng, D.; Li, R.; Sun, X. Superior energy capacity of graphene nanosheets for a nonaqueous lithium-oxygen battery. Chem. Commun. 2011, 47, 9438-9440. 
33. Yoo, E.; Nakamura, J.; Zhou, H. N-doped graphene nanosheets for Li-air fuel cells under acidic conditions. Energy. Environ. Sci. 2012, 5, 6928-6932.

34. Wang, H.; Yang, Y.; Liang, Y.; Zheng, G.; Li, Y.; Cui, Y.; Dai, H. Rechargeable Li-O 2 batteries with a covalently coupled $\mathrm{MnCo}_{2} \mathrm{O}_{4}$-graphene hybrid as an oxygen cathode catalyst. Energy Environ. Sci. 2012, 5, 7931-7933.

35. Wang, Z.-L.; Xu, D.; Xu, J.-J.; Zhang, L.-L.; Zhang, X.-B. Graphene oxide gel-derived, free-standing, hierarchically porous carbon for high-capacity and high-rate rechargeable $\mathrm{Li}-\mathrm{O}_{2}$ batteries. Adv. Funct. Mater. 2012, 22, 3699-3705.

36. Xiao, J.; Mei, D.; Li, X.; Xu, W.; Wang, D.; Graff, G.L.; Bennett, W.D.; Nie, Z.; Saraf, L.V.; Aksay, I.A.; et al. Hierarchically porous graphene as a lithium-air battery electrode. Nano Lett. 2011, 11, 5071-5078.

37. Wu, G.; Mack, N.H.; Gao, W.; Ma, S.; Zhong, R.; Han, J.; Baldwin, J.K.; Zelenay, P. Nitrogen-doped graphene-rich catalysts derived from heteroatom polymers for oxygen reduction in nonaquous lithium-oxygen battery cathodes. ACS Nano 2012, 6, 9764-9776.

38. Li, Y.; Wang, J.; Li, X.; Geng, D.; Banis, M.N.; Li, R.; Sun, X. Nitrogen-doped graphene nanosheets as cathode materials with excellent electrocatalytic activity for high capacity lithium-oxygen batteries. Electrochem. Commun. 2012, 18, 12-15.

39. Kumar, B.; Kumar, J.; Leese, R.; Fellner, J.P.; Rodrigues, S.J.; Abraham, K.M. A solid-state, rechargeable, long cycle life lithium-air battery. J. Electrochem. Soc. 2010, 157, A50-A54.

40. Kichambare, P.; Kumar, J.; Rodrigues, S.; Kumar, B. Electrochemical performance of highly mesoporous nitrogen doped carbon cathode in lithium-oxygen batteries. J. Power Sources 2011, 196, 3310-3316.

41. Kichambare, P.; Rodrigues, S.; Kumar, J. Mesoporous nitrogen-doped carbon-glass ceramic cathodes for solid-state lithium-oxygen batteries. ACS Appl. Mater. Interfaces 2012, 4, 49-52.

42. Kichambare, P.; Rodrigues, S. Mesoporous nitrogen-doped carbon-LiSICON glass ceramics as high performance cathodes in solid-state lithium-oxygen batteries. Energy Technol. 2013, 1, 209-211.

43. Wang, X.; Li, X.; Zhang, L.; Yoon, Y.; Weber, P.K.; Wang, H.; Guo, J.; Dai, H. N-doping of graphene through electrochemical reactions with ammonia. Science 2009, 324, 768-771.

44. Ozaki, J.; Kimura, N.; Anahara, T.; Oya, A. Preparation and oxygen reduction activity of BN-doped carbons. Carbon 2007, 45, 1847-1853.

45. Allen, B.L.; Kichambare, P.D.; Star, A. Synthesis, characterization, and manipulation of nitrogen-doped carbon nanotubes cups. ACS Nano 2008, 2, 1914-1920.

46. Tang, Y.; Allen, B.L.; Kauffman, D.R.; Star, A. Electrocatalytic activity of nitrogen-doped carbon nanotube cups. J. Am. Chem. Soc. 2009, 131, 13200-13201.

47. Gong, K.; Du, F.; Xia, Z.; Dustock, M.; Dai, L. Nitrogen-doped carbon nanotube arrays with high electrocatalytic activity for oxygen reduction. Science 2009, 323, 760-764.

48. Zhang, J.T.; Zhao, Z.H.; Xia, Z.H.; Dai, L.M. A metal-free bifunctional electrocatalyst for oxygen reduction and oxygen evolution reactions. Nat. Nanotechnol. 2015, 10, 444-452.

49. Li, X.; Wang, H,; Robinson, J.T.; Sanchez, H.; Diankov, G.; Dai, H. Simultaneous nitrogen doping and reduction of graphene oxide. J. Am. Chem. Soc. 2009, 131, 15939-15944. 
50. Panchakarla, L.S.; Subrahmanyam, K.S.; Saha, S.K.; Govindaraj, A.; Krishnamurthy, H.R.; Waghmare, U.V.; Rao, C.N.R. Synthesis, structure, and properties of boron- and nitrogen-doped graphene. Adv. Mater. 2009, 21, 4726-4730.

51. David, L.; Singh, G. Reduced graphene oxide paper electrode: Opposing effect of thermal annealing on Li and Na cyclability. J. Phys. Chem. C 2014, 118, 28401-28408.

52. Sandhu, S.S.; Fellner, J.P.; Brutchen, G.W. Diffusion-limited model for a lithium/air battery with an organic electrolyte. J. Power Sources 2007, 164, 365-371.

53. Ambrosi, A.; Chua, C.K.; Bonanni, A.; Pumera, M. Electrochemistry of graphene and related materials. Chem. Rev. 2014, 114, 7150-7188.

54. Komarova, N.S.; Krivenko, A.G.; Stenina, E.V.; Sviridova, L.N.; Mironovich, K.V.; Shulga, Y.M.; Krivchenko, V.A. Enhancement of the carbon nanowall film capacitance. Electron transfer kinetics on functionalized surface. Langmuir 2015, 31, 7129-7137.

55. Sun, Y. Lithium ion conducting membranes. Nano Energy 2013, 2, 801-816.

56. $\mathrm{Fu}, \mathrm{J}$. Fast $\mathrm{Li}^{+}$ion conducting glass-ceramics in the system $\mathrm{Li}_{2} \mathrm{O}-\mathrm{Al}_{2} \mathrm{O}_{3}-\mathrm{GeO}_{2}-\mathrm{P}_{2} \mathrm{O}_{5}$. Solid State Ionics 1997, 104, 191-194.

57. Leo, C.J.; Subba Rao, G.V.; Chowdari, B.V.R. Effect of $\mathrm{MgO}$ addition on the ionic conductivity of $\mathrm{LiGe}_{2}\left(\mathrm{PO}_{4}\right)_{3}$ ceramics. Solid State Ionics 2003, 159, 357-367.

58. Ding, N.; Chien, S.W.; Andy Hor, T.S.; Lum, R.; Zong, Y.; Liu, Z. Influence of carbon pore size on the discharge capacity of $\mathrm{Li}_{-} \mathrm{O}_{2}$ batteries. J. Mater. Chem. A 2014, 2, 12433-12441.

59. Xiao, J.; Wang, D.; Xu, W.; Wang, D.; Williford, R.E.; Liu, J.; Zhang, J.-G. Optimization of air electrode for Li/Air batteries. J. Electrochem. Soc. 2010, 157, A487-A492.

60. Yang, X.-H.; He, P.; Xia, Y.-Y. Preparation of mesocellular carbon foam and its application for lithium/oxygen battery. Electrochem. Commun. 2009, 11, 1127-1130.

61. Sun, B.; Wang, B.; Su, D.; Xiao, L.; Ahn, H.; Wang, G. Graphene nanosheets as cathode catalysts for lithium-air batteries with an enhanced electrochemical performance. Carbon 2012, 50, 727-733.

62. Jiang, D.E.; Sumpter, B.G.; Dai, S. Unique chemical reactivity of a graphene nanoribbon's zigzag edge. J. Chem. Phys. 2007, 126, 134701-134706.

63. Brownson, D.A.C.; Kampouris, D.K.; Banks, C.E. Graphene electrochemistry: Fundamental concepts through to prominent applications. Chem. Soc. Rev. 2012, 41, 6944-6976.

64. Trans, C.; Yang, X.Q.; Qu, D. Investigation of the gas-diffusion electrode used as lithium/air cathode in non-aqueous electrolyte and the importance of carbon material porosity. J. Power Sources 2010, 195, 2057-2063.

65. Barsoukov, E.; Macdonald, J.R. Impedance Spectroscopy: Theory, Experiment, and Applications, 2nd ed.; John Wiley and Sons: Hoboken, NJ, USA, 2005.

(C) 2015 by the authors; licensee MDPI, Basel, Switzerland. This article is an open access article distributed under the terms and conditions of the Creative Commons Attribution license (http://creativecommons.org/licenses/by/4.0/). 